\title{
UN “NUEVO-VIEJO” INTEGRANTE DEL ELENCO DE INSTRUMENTOS ÓSEOS DE PATAGONIA: LOS MACHACADORES ÓSEOS
}

\author{
ADÁN HAJDUK* Y MAXIMILIANO J. LEZCANO*
}

\begin{abstract}
RESUMEN
Se efectúa una reinterpretación del "marcado perimetral" en extremos articulares de huesos largos de guanaco de Patagonia, basada en la revisión bibliográfica, el análisis de material arqueológico y la experimentación simulativa. La presencia de supuestos indicios de esta técnica de fractura transversal de la diáfisis en general fue relacionada con la extracción de la médula y con la obtención de diáfisis como formas-base del tipo "tubos" o astillas para la confección de instrumentos. En este trabajo proponemos que las modificaciones generalmente asociadas al "marcado perimetral" no estarían relacionadas con la producción de la fractura transversal, sino que serían el resultado del uso del hueso como artefacto de percusión o machacado. La experimentación simulativa de técnicas de producción de fractura transversal y del uso de los huesos como machacadores permitió confirmar esta hipótesis. Hasta ahora este tipo de material nunca había llegado a formar parte del "elenco" estable de instrumentos óseos de Patagonia. A nivel hipotético, se propone que los machacadores óseos pudieron haber sido utilizados en el ablandamiento de carne deshidratada (charqui), carne fresca dura u otro tipo de material orgánico, como fibras vegetales, etc. Tampoco se puede descartar algún tipo de aplicación en la tecnología lítica.
\end{abstract}

PALABRAS CLAVES: guanaco, marcado perimetral, instrumentos óseos, machacadores, Patagonia.

\section{AN “OLD-NEW” MEMBER OF THE PATAGONIAN BONE INSTRUMENT SET: THE BONE HAMMERS}

\begin{abstract}
Based on existing literature, the analysis of archaeological material, and experimental work, we offer a reinterpretation of the pattern "perimetral marking" of guanaco bone shafts in Patagonia. Previously this technique of transversal fracture was related to marrow extraction and/or the preparation of 'tube' or splinter pre-forms for the production of bone tools. In this paper we propose that bone modification classified as "perimetral marking" is the outcome of the use of bone as a percussion or pounding artifact rather than an attempt to obtain a transversal fracture. This hypothesis is supported by experimental simulation of both techniques of transversal fracture and the use of the bones as pounders. Until now this type of material has never been considered as part of the repertoire of Patagonian bone instruments. Hypothetically it is proposed that these bone instruments may have been used to

* CONICET y Museo de la Patagonia "F. P. Moreno", Centro Cívico s/n (8400), San Carlos de Bariloche, Pcia. de Río Negro. E-mail: adamhajduk@bariloche.com.ar
\end{abstract}


soften jerky or hard fresh meat, or to process other types of organic materials such as vegetal fibers, etc. We cannot at this stage overrule the possibility that they might have been used in conjunction with stone tools.

KEY WORDS: guanaco, perimetral marking, bone instruments, pounders, Patagonia.

\section{INTRODUCCIÓN}

En los sitios arqueológicos de Patagonia Centro-Meridional son comunes las menciones a una supuesta técnica para lograr la fractura transversal de extremos articulares de huesos largos de guanaco, conocida como de "marcado perimetral". La presencia de estos huesos con fractura transversal y supuestos indicios de esta técnica en general fue relacionada con la extracción de la médula y con la obtención de diáfisis como formas-base ("tubos") o astillas para la confección de instrumentos.

En este trabajo proponemos una reinterpretación del "marcado perimetral" en extremos de huesos largos de guanaco procedentes de sitios arqueológicos de Patagonia. Efectuamos un análisis bibliográfico del tema, analizamos el material arqueológico y llevamos a cabo experiencias simulativas de la producción de fracturas transversales y de la utilización posterior de los huesos. Finalmente, introducimos la problemática de la aplicación de este tipo de instrumentos y exponemos algunas hipótesis en relación.

Nosotros planteamos que los atributos generalmente asociados al "marcado perimetral" no estarían relacionados con una técnica específica para lograr la fractura transversal de los huesos sino que serían el resultado del uso del hueso como instrumento de percusión o machacado. Hemos presentado un avance sobre este tema en las $\mathrm{V}$ Jornadas de Arqueología de la Patagonia del 2002 $y$ en Hajduk et al. (2004).

Estos materiales casi siempre fueron considerados como parte de los conjuntos arqueofaunísticos, con lo cual nunca llegaron a formar parte del "elenco estable" de instrumentos óseos de Patagonia. Como comentara Semenov (1981: 34) La masa de instrumentos de hueso es poco favorable para su diferenciación y determinación, por lo que permanecen a menudo ignoradas, escapan a la atención del investigador y se las vincula a los restos de la fauna. El párrafo de Semenov es particularmente oportuno en el caso de artefactos o instrumentos óseos de carácter expeditivo, mínimamente modificados en su confección y uso.

Los huesos que motivan este trabajo encierran el "misterio" de uno de los útiles expeditivos más comunes y típicos del extremo sur de América: los machacadores óseos.

\section{ANTECEDENTES BIBLIOGRÁFICOS}

La amplia proyección en el tiempo del hallazgo y mención de los huesos con fractura transversal (en adelante FT) por "marcado perimetral" (en adelante "MP") en la arqueología de Patagonia justificó un análisis detallado pero seguramente perfectible de los antecedentes bibliográficos sobre el tema. Un esfuerzo anterior en ese sentido puede encontrarse en Muñoz y Belardi (1998). Como veremos más adelante, consideramos que la mayor parte de las menciones de huesos con "MP" aquí incluidas se refieren al tipo de materiales que motivó este trabajo, ya sea por las descripciones, las ilustraciones o porque hemos tenido oportunidad de observar información gráfica original o los mismos materiales. En la Fig. 1 se muestra la localización de los sitios arqueológicos considerados en este trabajo, con la correspondiente referencia bibliográfica. A fin de resumir el texto, la totalidad de los nombres de los sitios se incluyen en esta figura.

La primera cita del "marcado perimetral" en nuestro medio para extremos articulares de huesos de guanaco es la de Mengoni Goñalons y Silveira (1976: 264) para el sitio Cueva de Las Manos del Alto Río Pinturas, quienes lo definen como un ... marcado circular transversal, el cual se habría logrado aserrando superficialmente el hueso con un instrumento, para luego fracturarlo con un golpe contundente... Posteriormente, Silveira (1979:233) observa la Cueva Grande del Arroyo Feo ...una fractura perpendicular o transversal en huesos largos, por lo general cerca de las epífisis, que requirió un marcado previo para que la fractura se haya producido de ese modo, es decir, una técnica para obtener una ruptura neta de la diáfisis para una ulterior utilización de la misma. Mengoni Goñalons (1982:90 y 1988) lo 


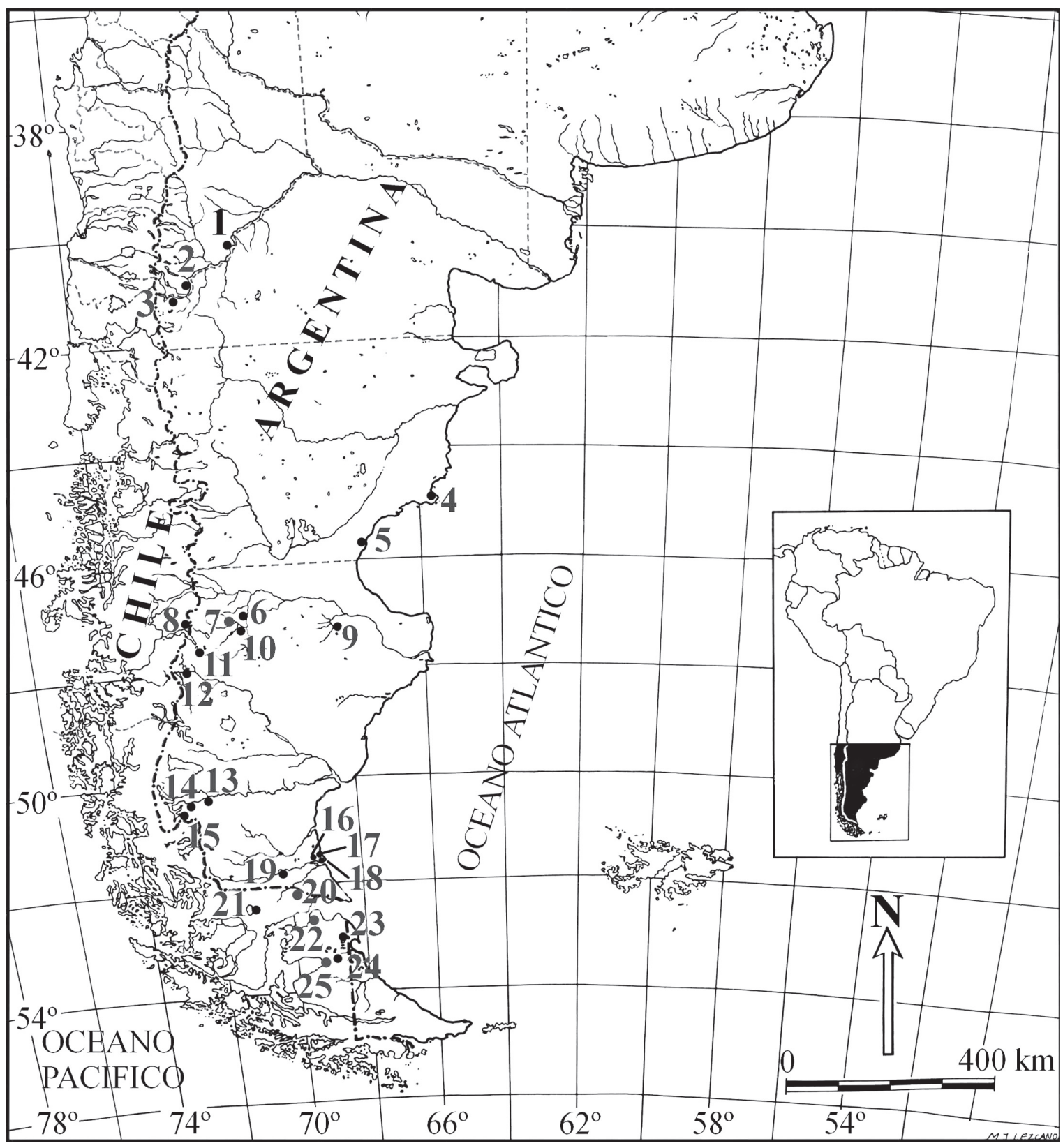

Fig. 1 Mapa con la ubicación de los sitios arqueológicos citados en el texto. 1: Cueva Epullán Grande (Lezcano obs. pers.), 2: Cueva del Manzano - Ayo. Corral (Hajduk obs. pers.), 3: Cueva El Trébol (Hajduk et al. 2004), 4: Bahía Camarones (Caviglia com. pers.), 5: Bahía Solano (Caviglia y Borrero 1978), 6: Cueva Grande del Arroyo Feo (Silveira 1979), 7: "Parapeto" del lago Buenos Aires (Gradín 1976), 8: Alero Entrada Baker (Mena y Jackson 1991), 9: Cuevas 3 y 13 de Los Toldos (Miotti 1998), 10: Cueva de las Manos-Alto Río Pinturas (Mengoni Goñalons y Silveira 1976) y Alero Charcamata (Aguerre 1994), 11: Cerro de los Indios 1 (Mengoni Goñalons 1999), 12: Cerro Casa de Piedra 7 (De Nigris 2005$), 13:$ Campo del Lago 2 (Muñoz 1999), 14: Alice 1 (Borrero et al. 1998-1999), 15: Chorrillo Malo 2, Cerro León 1 y Cerro Verlika (Franco et al. 1999), 16: Hill Station (Hajduk obs. pers.), 17: dos sitios en la margen norte de la ría del Gallegos (Miotti 1998), 18: RUD01BK (Mansur et al. 2004), 19: Las Buitreras (Caviglia com. pers.), 20: Pali Aike (Nami 1999), 21: Cañadón Leona (Bird 1993), 22: Punta Baxa 4 y 7, Bahía Azul 22 y Punta Anegada 33 (Martin 2004), 23 : La 11 y 12 (Massone et al. 1993), 24: Tres Arroyos 1 y 7 (Massone et al. 1993) y 25: Marazzi 34 y Bahía Inútil 17 (Martin 2004$).$ 
define como un... marcado perimetral completo o incompleto (mediante aserrado o incisión profunda), que conduce o delimita la orientación de las ondas de fractura. Agrega que de no existir un marcado previo, la fractura puede ser transversal, pero de tipo irregular, generalmente oblicua al eje longitudinal del hueso. Entre otras citas más recientes, para Cueva de Los Toldos (Miotti 1998), Cerro de los Indios I (Mengoni Goñalons 1999) y Cerro Casa de Piedra 7 (De Nigris 2005) los autores coinciden con estas definiciones.

El "marcado perimetral" fue citado en otras publicaciones (Fig. 1), pero poco se agrega sobre sus características. En ese sentido, Massone et al. (1993: 97) indican que las fracturas transversales de epífisis con "MP" se habrían logrado ...por "piqueteo" en la base de las epífisis. Miotti indica que la mayoría de las epífisis de guanaco fueron fracturadas a partir de un surco perimetral a la diáfisis, cuyo borde de fractura ... fue regularizado por una serie de retoques alrededor del surco formatizando una superficie de fractura recta $y$ transversal al eje mayor del hueso, o que el surco mismo fue efectuado por fricción o picado (Miotti 1998:78). Prieto et al. (1998: 90) mencionan para el sitio de Bird "Cañadón Leona" que los huesos con "MP" aparecen con ... huellas de machacado en parte de su radio o con huellas de microlascados. Muñoz y Belardi (1998: 108) observan en el mismo material que la sección de un hueso con FT y "MP" muestra lascados cuyos negativos se orientan en dirección a la epífisis.

En Patagonia los huesos con mención de "MP" corresponden principalmente a guanaco, incluyendo extremos articulares proximales y distales de fémur, tibia, húmero y radio-cúbito, en los dos últimos con menos casos en el extremo proximal (en adelante px.). En menor proporción se mencionan sólo extremos distales (en adelante ds.) de metapodio, para la Cueva de Los Toldos (Miotti 1998) y el Cerro de los Indios I (Mengoni Goñalons 1999:147 y 186) y en un solo caso un proximal de escápula (Hajduk et al. 2004). Sin embargo, también se los ha registrado en restos de otras especies, como en huemul (De Nigris 2005), en Rehidae (Caviglia y Borrero 1978, Caviglia com. pers. y Miotti 1998:186) y choique (Pterocnemia pennata) (Miotti 1998:193). En adelante las menciones sobre material óseo, salvo aclaración respectiva, se referirán a huesos de guanaco.
En general los extremos articulares incluyen entre $1 / 3$ y $1 / 5$ de la longitud del hueso, aunque pueden llegar a $1 / 2$ y a 1/6. Corresponden mayormente a ejemplares adultos y adultos jóvenes. También suelen aparecer fragmentos de diáfisis y lascas óseas con evidencia de "MP" (Mengoni Goñalons 1999, Mengoni Goñalons y De Nigris 1999 y De Nigris 2003).

Los huesos con "MP" muestran una amplia dispersión en Patagonia, abarcando diferentes ambientes, desde Patagonia Central hasta el norte de Tierra del Fuego, incluyendo la costa atlántica (Fig. 1). Aparecen en niveles de diferente antigüedad y en sitios indicadores de diferentes actividades, tanto de "caza-destazamiento" (Massone et al. 1993: 97) como residenciales (la gran mayoría de los sitios aquí citados).

Silveira (1979) menciona que en el sitio Cueva de las Manos y en un parapeto de la meseta del lago Buenos Aires (Gradín 1976) la técnica del "MP" parece privativa de momentos tardíos (presumiblemente prehispánicos), pero aparece también en capas más antiguas de Arroyo Feo por lo que concluye que esta técnica se remonta a épocas más antiguas. Muñoz y Belardi (1998) y De Nigris (2003:191) coinciden con Silveira. Prieto et al. (1998) indican que no los encuentran en sitios históricos de superficie en Tierra del Fuego y tampoco en sitios tempranos. Aparentemente no habría registros posthispánicos. Los extremos temporales conocidos oscilan entre los 700 y 990 años AP (Gradín et al. 1976, Mengoni Goñalons 1999 y Muñoz 2000), entre los 6.000 y 7.500 y los 8.000 y 11.000 (Miotti 1998 y De Nigris 2003). De Nigris menciona para el 8.000 sólo astillas con "MP".

La frecuencia de aparición de huesos con "MP" es variable en una misma secuencia estratigráfica, con porcentajes de extremos articulares con "MP" sobre el total de articulaciones de entre 5,5 y 26,5\% para el sitio Casa de Piedra 7 (De Nigris 2005) y de entre el 5,5 y el 12,5\% para el sitio Cerro de los Indios 1 (Mengoni Goñalons 1999). Como opina De Nigris (2003), pareciera haber un aumento hacia los niveles tardíos.

Los huesos con "MP" han sido objeto de diferentes interpretaciones a lo largo del tiempo, incluyéndoselos dentro de los conjuntos arqueofaunísticos en diferentes categorías. 
Usualmente fueron considerados como desechos del trabajo de manufactura para la obtención de diáfisis como formas-base del tipo "tubos" o astillas (Gradín 1976, Mengoni Goñalons y Silveira 1976, Silveira 1979, Borrero 1994-1995, Miotti 1998, Muñoz 1999, De Nigris 2003, etc.).

En el caso de los "tubos" de diáfisis de guanaco, varios autores destacan su falta en el registro arqueológico (Mengoni Goñalons y Silveira 1976:264, Silveira 1979, Muñoz y Belardi 1998) mientras que otros citan su ocasional presencia (Scheinsohn 1997 y Miotti 1998). La primera autora menciona "tubos" de hemidiáfisis y diáfisis enteras de huesos largos de guanaco con extremos levemente "biselados" (¿aserrados?) para un nivel de un sitio de la isla grande de Tierra del Fuego.

Diferente es el caso de adornos e instrumentos en forma de "tubo" hallados en Patagonia. Éstos en general están confeccionados con huesos de animales menores, como aves y cánidos, seccionados transversalmente por "aserrado perimetral" superficial y quiebre posterior. Nami y Borella (1999:241) mencionan huellas de "cercenamiento" (o de aserrado perimetral) para la elaboración de artefactos sobre restos de cetáceos de la costa fueguina y efectúan la experimentación de la técnica. Ya fuera de Patagonia, Acosta (2000) realiza comentarios sobre esta técnica concreta de seccionamiento del hueso, que hasta el momento no vemos asociada con el "MP" de la bibliografía, aunque sí se la ha mencionado. Este autor estudia huesos de cérvidos con huellas de "aserrado perimetral" provenientes del nordeste de la provincia de Buenos Aires (bajíos ribereños). El aserrado suele abarcar toda o casi toda la sección del hueso, ya que con esta técnica más cuidadosa lo que se buscaba era el seccionamiento transversal del hueso sin provocar mayores daños en los bordes de fractura, con el fin de utilizar las diáfisis como formas-base del tipo "tubos". Aclara que las huellas de aserrado perimetral son diferentes a las de "marcado o surco perimetral", cuyos fines son más ambiguos (Acosta 2000).

De Nigris (2003) opina que la presencia de pequeños fragmentos diafisiarios y de lascas óseas de huesos largos de guanaco con "MP" ...se relacionan con el consumo de los huesos largos en la localidad o con el desarrollo de ciertas actividades tecnológicas (e.g. confección de instrumental óseo; ver Miotti 1998).
También se los consideró como producto de una modalidad de fractura para la extracción de la médula (Gradín 1976:329, Caviglia y Borrero 1978, Massone et al. 1993, Borrero 1994-1995, Muñoz 1999, Mengoni Goñalons 1999 y De Nigris 2003) y como un método de fractura para facilitar el trozamiento y el transporte de presas congeladas y/o con rigor mortis (Prieto MS en Muñoz y Belardi 1998:113, Muñoz y Belardi 1998 y Massone et al. 1993).

Otra postura a nivel de hipótesis sugiere que el "MP" podría estar relacionado con una particular forma de cocción. Gifford-González (1989:219 fig. 26) ilustra dos extremos distales de húmero de cebra de los nativos Dassanetch de África (noreste de lago Turkana) quienes, según le informaron, frecuentemente habrían efectuado el proceso de fractura de las diáfisis para reducir el tamaño de los huesos para su cocción por hervido. Las modificaciones que se observan en los planos de fractura del material de esa ilustración se asemejan a las del "MP" de nuestra bibliografía, como observa Mengoni Goñalons (1999:87). Mengoni Goñalons (1999) indica también, que en el sitio Cerro de los Indios 1 la fractura transversal por "MP" ...puede asociarse con prácticas culinarias específicas que involucren el calentamiento o cocción de los huesos... y, en ese sentido, también con la obtención de la médula.

Los extremos articulares con "MP" fueron considerados como instrumentos en muy pocas oportunidades: asociados con el acabado de material lítico por percusión, aunque sin mención de "MP" (Bird 1993:68), sin asociación funcional en unos casos, como mango de instrumentos líticos en otros (Miotti 1998:177) y como "machacadores" (Hajduk et al. 2004).

En 1936 Junius B. Bird (1993:68) estudia los extremos articulares de huesos largos de guanaco del sitio Cañadón Leona, mencionando que Huesos de patas de guanaco de 3 a 5 pulgadas, quebrados perpendicularmente desde la articulación, son los artefactos más comunes. Sus extremos astillados muestran que ellos se han usado como martillos. Efectuó la experimentación del uso de estos huesos como percutor y observó que los ...extremos astillados solamente se pueden duplicar cuando la pieza se usa para machacar más fuerte que lo necesario para desalojar cualquier resto de médula que pudiera haber quedado adentro. En cuanto a su aplicación, Bird propuso que habrían sido utilizados en una fase 
TABLA 1. Material arqueológico analizado.

\begin{tabular}{|l|c|c|c|c|c|c|c|c|c|c|c|c|c|}
\hline \multirow{2}{*}{ Sitio } & \multicolumn{2}{|c|}{ Metapodio } & \multicolumn{2}{c|}{ Fémur } & \multicolumn{2}{c|}{ Tibia } & \multicolumn{2}{c|}{ Escápula } & \multicolumn{2}{c|}{ Húmero } & \multicolumn{2}{c|}{ Radio-cúbito } & \multirow{2}{*}{ Totales } \\
\cline { 2 - 13 } & PX & DS & PX & DS & PX & DS & PX & DS & PX & DS & PX & DS & \\
\hline El Trébol & - & - & - & - & 1 & - & 1 & - & 1 & 1 & - & - & 4 \\
\hline Ayo. Corral & - & - & 1 & - & - & - & - & - & - & - & 1 & - & 2 \\
\hline Bahía Solano & - & - & - & 4 & & 5 & - & - & - & 1 & 2 & 7 & 19 \\
\hline Arroyo Feo & - & - & 2 & - & 3 & 1 & - & - & - & - & - & 2 & 8 \\
\hline Los Toldos 3 y 13 & - & - & 7 & 2 & 3 & - & - & - & 1 & & 1 & 1 & 17 \\
\hline Hill Station & - & - & - & 2 & - & 1 & - & - & - & 1 & - & - & 4 \\
\hline RUD01BK & & & 2 & & & & & & 1 & & 3 & & 6 \\
\hline La Leona & - & - & 5 & 14 & 6 & 2 & - & - & 1 & 5 & - & 8 & 41 \\
\hline Totales & - & 2 & 17 & 22 & 13 & 9 & 1 & - & 4 & 8 & 7 & 18 & 101 \\
\hline
\end{tabular}

PX: proximal y DS: distal.

avanzada de la elaboración de boleadoras de piedra para eliminar pequeñas irregularidades.

Hay que destacar que Bird es el primero que identifica como instrumentos al tipo de huesos motivo de nuestro trabajo, reconociendo los rastros de uso y asignándole función y aplicación, aunque sus hipótesis no resultaron creíbles (Borrero 1994-1995:13). Bird no menciona el "MP" porque identifica sus supuestos atributos como evidencias de uso, aunque sí lo indican Prieto et al. (1998) y Muñoz y Belardi (1998) cuando estudian el propio material de Bird.

Hajduk et al. (2004) reconocen como instrumentos a extremos de huesos de guanaco con modificaciones como las asociadas al "MP", indicando su uso como "machacadores". Agregan que las alteraciones producto del uso del hueso como "machacador" podrían enmascarar evidencias de un posible marcado perimetral para lograr la fractura transversal. Destacan que estos machacadores podrían estar presentes en otros sitios, en donde aún no fueron detectados como tales.

Martin (2004:111), luego de leer nuestro manuscrito, menciona para el norte de la isla grande de Tierra del Fuego (Primera Angostura y Bahía Inútil) seis sitios de superficie con artefactos óseos representados por la identificación de corte perimetral sobre huesos de guanaco.

En otros trabajos se mencionan huesos de guanaco con fractura transversal con "marcado o surco perimetral" (en algunos casos con ilustraciones o indicaciones sugerentes) aunque sin mayores comentarios. Las referencias se encuentran en la Fig. 1. Vale la aclaración hecha al principio del texto, en el sentido de que el análisis bibliográfico que hemos llevado a cabo es seguramente perfectible y que otros sitios publicados pueden contar con este tipo de material aunque no se los menciona.

\section{RESULTADOS}

\section{EL MATERIAL ARQUEOLÓGICO ESTUDIADO}

Describiremos brevemente algunos materiales arqueológicos con modificaciones como las asociadas comúnmente al "marcado perimetral", tanto publicados como inéditos (Figs. 1 y 2, Tabla 1).

De un nivel cerámico antiguo del sitio El Trébol (Hajduk et al. 2004) proceden cuatro extremos articulares de huesos largos (más uno plano) de guanaco con una serie de modificaciones en los extremos rotos de las diáfisis (Fig. 2a). Estas modificaciones se repiten en el resto del material analizado procedente de otros sitios.

Entre las modificaciones más notorias (Fig. 3b) se encuentran los negativos de lascados laterales que parten del plano transverso de rotura y avanzan sobre las caras externa e interna (cavidad medular) de la diáfisis (Figs. 3b y 9a, b, c). En la cara externa estos negativos tienden a ser notablemente más largos y anchos que los internos, reflejando desprendimientos delgados escamosos, en ambos casos con extremos que frecuentemente terminan en charnela. La sucesión de negativos de lascados laterales externos y escamosos suele producir un aspecto escalonado. Algunas partes de la sección adelgazadas por el desprendimiento de lascas forman un filo destacado. Las superficies del perímetro de rotura muestran lascas contiguas plegadas y adheridas (no desprendidas) con talones filiformes deformados por aplastamiento y peque- 


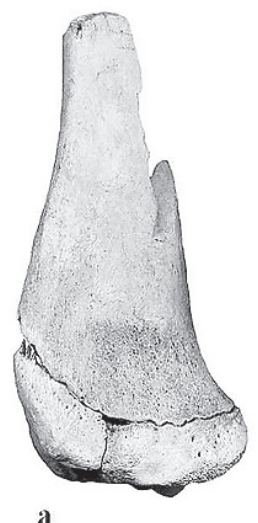

a

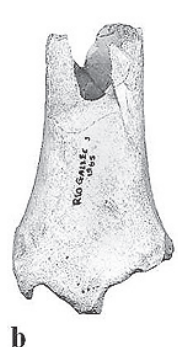

b

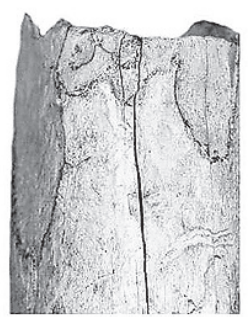

$\mathbf{g}$

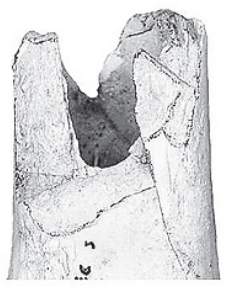

h

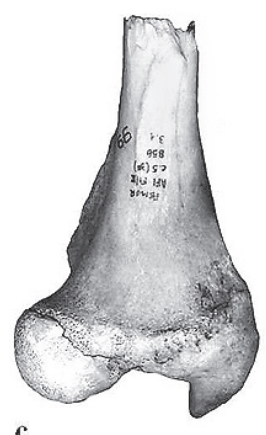

c

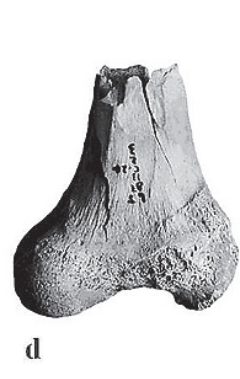

$5 \mathrm{~cm}$

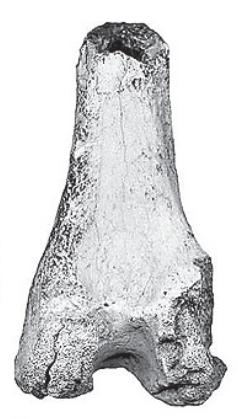

e

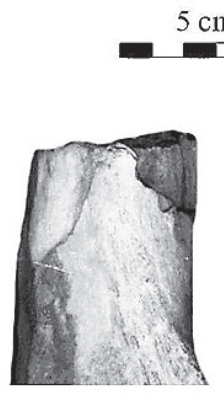

i j

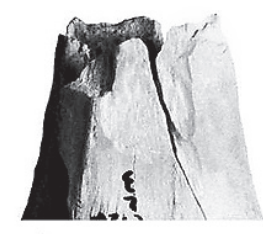

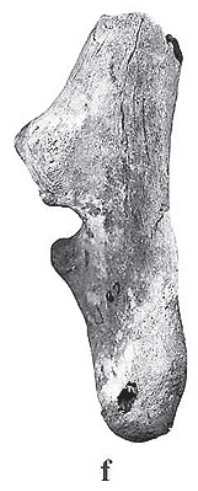

f

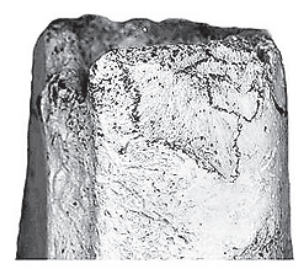

li

$5 \mathrm{~cm}$

Fig. 2 Extremos articulares de guanaco con modificaciones del tipo "marcado perimetral", en este trabajo interpretados como "machacadores". a) px. de tibia del sitio El Trébol, b) - g) ds. de tibia de Hill Station, c) - h) px. de fémur de Arroyo Feo, d) - i) px. de fémur de Los Toldos, e) - j) ds. de fémur de Hill Station y f) px. de radio-cúbito de Cueva del Manzano - Ayo. Corral.

ños negativos de lascados contiguos en el plano de fractura, paralelos a la pared del hueso. Los sectores más espesos y resistentes del perímetro suelen ser romos o mellados. En todos los casos el perímetro de la diáfisis muestra desprendimientos de sección que reducen el perímetro hasta $1 / 4$ del total. Como caso excepcional, un extremo px. de tibia (Fig. 2a) muestra claros indicios de uso en ese estado.

Estas modificaciones indican que estos huesos fueron utilizados para golpear superficies resistentes en el sentido longitudinal del hueso, a modo de machacador (Figs. 2 y 3). La coincidencia de los tributos de este material con los generalmente asociados al "MP" en otros sitios fue decisiva en la evaluación del material que pasamos a describir a continuación y en el material de la bibliografía. En esta parte del trabajo asignamos al material la identidad de instrumentos del tipo machacador, hipótesis que en el capítulo siguiente pondremos a prueba por medio de la experimentación simulativa.
En niveles tempranos de la Cueva Epullán Grande (Lezcano obs. pers.) se registran fragmentos de diáfisis con lascados sucesivos laterales a modo de "MP", entre otros restos, que podrían pertenecer a instrumentos del tipo de machacadores. También se los encuentra en el sitio Cueva del Manzano - Arroyo Corral (Hajduk obs. pers.), junto con dos ejemplares de machacadores (Fig. 2f).

En el conjunto de Bahía Solano (Caviglia y Borrero 1978) los machacadores son frecuentes. Por gentileza de S. Caviglia hemos accedido a información gráfica inédita con detalles de modificaciones atribuidas al "marcado perimetral" sobre 19 extremos de huesos largos de guanaco y 3 de choique (Pterocnemia pennata). Predominan claramente los extremos distales $(88,24 \%)$, en proporciones casi iguales de derechos e izquierdos. Estas porciones involucran algo menos de $1 / 2$ del hueso (5,88\%), algo más de $1 / 3$ (17,65\%), 1/3 (35,29\%) y $1 / 4$ (41,18\%). Cabe destacar que los perímetros de las diáfisis con 
rastros de uso están en su mayoría incompletos. En un sitio de Bahía Camarones (Caviglia com. pers.) se encuentran materiales similares.

Hemos analizado ocho de estos instrumentos procedentes del sitio Cueva Grande del Arroyo Feo (Silveira 1979). Las porciones oscilan entre $1 / 4$ y $1 / 3$ del largo del hueso. En todos los casos se observan rastros de uso como los asociados al "MP" (Fig. 2c, i).

De los sitios Cuevas 3 y 13 de Los Toldos (Miotti 1998) hemos observado 17 extremos articulares con supuesto "MP", que en general presentan rastros de uso por machacado (Fig. 2d, j). Lo mismo podemos decir de los materiales de los sitios Chorrillo Malo 2, Cerro León 1 y Cerro Verlika (Franco et al. 1999), RUD01BK (Mansur et al. 2004), Las Buitreras (Caviglia com. pers.) y de dos sitios en la margen norte de la ría del Gallegos (Miotti 1998), de los cuales vimos fotografías o el material mismo.

En el sitio de superficie Hill Station (Hajduk obs. pers.), en la margen norte de la ría del Río Gallegos, se recuperaron cuatro machacadores típicos (Figs. 2b, e, g, k, 3 y 9a, b y c). Alan Bryan vio este material en el año 1976; su primera reacción fue hacer el ademán de percutir con ellos ...

Uno de nosotros (A. H.) tuvo oportunidad de revisar el material del sitio Cañadón Leona

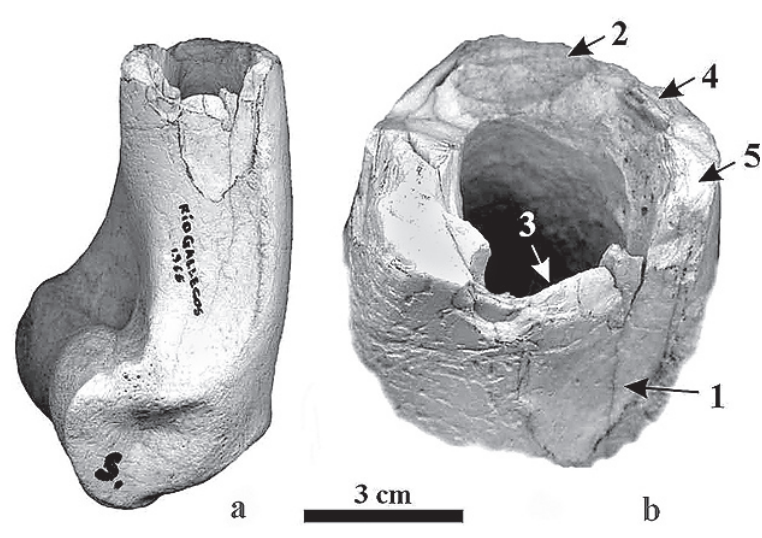

Fig. 3 Machacador arqueológico del sitio Hill Station. a) extremo ds. de húmero izq. de guanaco y b) detalle de la superficie activa del mismo hueso; 1: negativos de lascados laterales, 2: negativos de lascados contiguos en el plano de fract., 3: filo, 4: lascas adheridas contiguas y 5 : superficie roma.
(Bird 1993), depositado en el American Museum of Natural History, el mismo que estudiaron $\mathrm{Mu}-$ ñoz y Belardi (1998) y Prieto et al. (1998). De 43 extremos articulares que se conservaron de los 200 que originalmente había encontrado Bird, en 41 se observaron rastros de uso como machacador, como el mismo autor propuso originalmente. Algunos de ellos fueron ilustrados por Bird (1993).

En el material analizado no hemos observado rastros de formatización ni hemos registrado indicios de alguna técnica de marcado perimetral para la producción de la fractura transversal, como marcas de percusión o surco por aserrado. En parte del material analizado no observamos huellas de uso pasivo (pulimento y brillo) en las zonas de aprehensión (Semenov 1981:31).

\section{LA EXPERIMENTACIÓN SIMULATIVA}

El análisis de material arqueológico con modificaciones comúnmente asociadas al "marcado perimetral" nos permitió relacionar ciertos daños en las fracturas transversales de las diáfisis con los que podrían darse por el uso del hueso como instrumento en tareas que implicaran percusión o machacado. Con el fin de poner a prueba esta hipótesis de trabajo, llevamos a cabo la replicación de la fractura transversal con o sin marcado perimetral y del posterior uso de la forma obtenida como "machacador".

Se trabajó con huesos frescos de ciervo colorado (Cervus elaphus), cuyos huesos largos son semejantes en tamaño y forma a los de guanaco. La casi totalidad de los huesos correspondían a ejemplares adultos (con las epífisis fusionadas). Los huesos se recibieron descarnados en su mayor parte, operación que completamos para facilitar el trabajo. En una primera instancia la experimentación se realizó con huesos frescos, obtenidos a cuatro días del faenamiento de los animales. En ese lapso habían sido conservados en heladera entre 2 y $5^{\circ} \mathrm{C}$. En una segunda etapa se trabajó con parte del mismo lote de huesos, pero luego de quedar expuestos al aire por 30 días (bajo techo y con clima frío). En una tercera y en una cuarta serie de experiencias se trabajó nuevamente con material fresco. En total se experimentó con 45 extremos articulares px. y ds. de fémur, tibia, húmero y radio-cúbito (Tabla 2 ). 
TABLA 2. Técnicas de obtención de fractura transversal por marcado perimetral y material experimental utilizado.

\begin{tabular}{|c|c|c|c|c|c|c|c|c|c|c|c|c|c|c|c|c|c|c|c|c|c|c|}
\hline \multirow{2}{*}{$\begin{array}{c}\text { Técnicas } \\
\text { FT } \\
\end{array}$} & \multicolumn{3}{|c|}{ FT } & \multicolumn{3}{|c|}{ FOML } & \multicolumn{3}{|c|}{ FOL } & \multicolumn{3}{|c|}{$\mathrm{FO}$} & \multicolumn{3}{|c|}{ FOA } & \multicolumn{3}{|c|}{ FOMA } & \multicolumn{3}{|c|}{ FL } & \multirow{2}{*}{ Totales } \\
\hline & $\mathrm{R}$ & I & A & $\mathrm{R}$ & I & A & $\mathrm{R}$ & I & A & $\mathrm{R}$ & I & A & $\mathrm{R}$ & I & A & $\mathrm{R}$ & $\mathrm{I}$ & A & $\mathrm{R}$ & $\mathrm{I}$ & A & \\
\hline 1 (sin MP) & & & & & & & & 1 & & & & & & & 4 & & 3 & & & & & 8 \\
\hline $4-8$ & & 1 & & & & & & & & & 3 & & & 1 & 2 & & & 2 & & & & 9 \\
\hline $15-30$ & & & & & 1 & & & 1 & & & 2 & 1 & & 1 & 5 & & & & & & 1 & 12 \\
\hline+40 & & 1 & & & 1 & & & 1 & 1 & & & & 1 & 2 & 2 & & & 1 & & & & 10 \\
\hline aserrado & 1 & 2 & & & 2 & & & 1 & & & & & & & & & & & & & & 6 \\
\hline Totales & 1 & 4 & 0 & 0 & 4 & 0 & 0 & 4 & 1 & 0 & 5 & 1 & 1 & 4 & 13 & 0 & 3 & 3 & 0 & 0 & 1 & 45 \\
\hline
\end{tabular}

1 (sin MP): un golpe sin MP, 4-8 ...: número de percusiones del MP, FT: fractura transversal, FOML: fract oblicua muy leve, FOL: fract. oblicua leve, FO: fract. oblicua, FOA: fract. oblicua acentuada, FOMA: fract. oblicua muy acentuada, FL: fract. longitudinal, R: fractura transversal regular, I: irregular y A: astillada.

La forma y el aspecto que toman las fracturas en un hueso largo dependen de la estructura del tejido compacto, formada por unidades cilíndricas (osteones o sistema de Havers) orientadas en forma paralela al eje longitudinal del hueso. La dirección de la fractura tiene que ver con la disposición y porcentaje de los componentes orgánico (colágeno) e inorgánicos (cristales de apatita) del hueso y con la rotación de las epífisis con respecto a las diáfisis (torsión sigmoidea). Esto último se da en húmero, fémur, tibia y en menor medida en radio-cúbito (Miotti 1998:76 y los autores allí citados).

En la Fig. 4 se expone el criterio que utilizamos en la experiencia para clasificar los distintos tipos

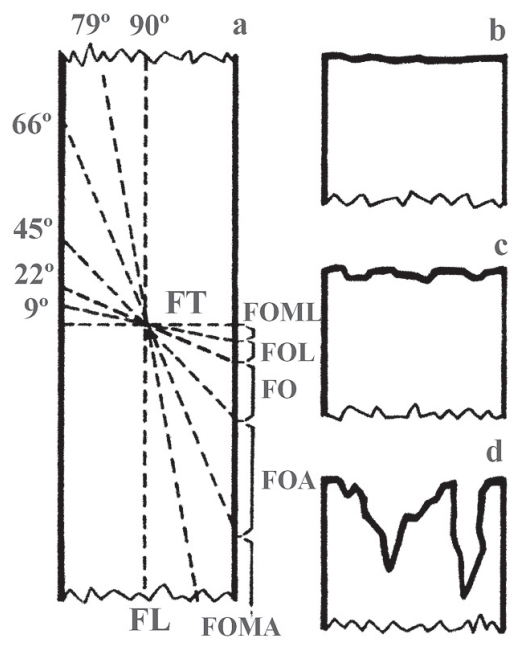

Fig. 4 Tipos de fracturas experimentales obtenidas sobre diáfisis según ángulo y forma. En a) FT: fractura transversal, FOML: fract. oblicua muy leve, FOL: fract. oblicua leve, FO: fract. oblicua, FOA: fract. oblicua acentuada, FOMA: fract. oblicua muy acentuada y FL: fract. longitudinal, en b) fractura transversal regular, c) irregular y d) astillada. de fracturas obtenidas. Partiendo del plano ideal transverso como ángulo 0 , éste se va incrementando hasta que la fractura se hace paralela al eje longitudinal del hueso $\left(90^{\circ}\right)$. La medición del ángulo se obtiene uniendo los extremos más salientes y los más entrantes del perímetro de fractura.

Para la obtención de la fractura transversal regular de huesos largos de guanaco es probable que se hayan aplicado una o más técnicas particulares de fractura (como sugieren Silveira 1979:233 y Mengoni Goñalons 1982), desde alguna sencilla técnica por uno o más golpes hasta el acondicionamiento de la diáfisis mediante un marcado perimetral de diversa complejidad por percusión o aserrado.

Un caso etnográfico es el que menciona Binford (1985, com. pers. en Gifford-González 1989:200), donde indica haber visto a los navajo del este de Arizona fracturar transversalmente los huesos largos frescos de oveja para reducirlos al tamaño del recipiente de cocción. Esto lo lograban mediante el percutido de la parte media de la diáfisis con un cuchillo o hachuela, originando una muesca o incisión para luego fracturar el hueso golpeándolo sobre el ángulo agudo de un yunque de piedra.

Los procedimientos utilizados por nosotros en parte de la experiencia coinciden con lo observado por Binford.

\section{Simulación de técnicas para lograr la fractura transversal}

En la experiencia ensayamos la producción de fracturas transversales por medio de diferentes técnicas con o sin marcado perimetral (Fig. 5a, b, c y Tabla 3): 
TABLA 3. Técnicas de obtención de la fractura transversal por marcado perimetral y resultados obtenidos.

\begin{tabular}{|c|c|c|c|c|c|c|c|c|c|}
\hline \multirow{2}{*}{$\begin{array}{c}\text { Técnicas } \\
\text { FT }\end{array}$} & \multicolumn{2}{|c|}{ Fémur } & \multicolumn{2}{|c|}{ Tibia } & \multicolumn{2}{|c|}{ Húmero } & \multicolumn{2}{|c|}{ Radio-cúbito } & \multirow{2}{*}{ Totales } \\
\hline & PX & DS & PX & DS & PX & DS & PX & DS & \\
\hline $1(\sin M P)$ & 1 & 2 & 2 & - & - & 3 & - & - & 8 \\
\hline $4-8$ & 3 & 1 & - & - & 2 & 2 & - & 1 & 9 \\
\hline $15-30$ & 1 & - & 3 & 4 & - & 1 & 2 & 1 & 12 \\
\hline+40 & 3 & 5 & 1 & 1 & - & - & - & - & 10 \\
\hline aserrado & 1 & 1 & 2 & 2 & - & - & - & - & 6 \\
\hline Totales & 9 & 9 & 8 & 7 & 2 & 6 & 2 & 2 & 45 \\
\hline
\end{tabular}

1 (sin MP): un golpe sin marcado perimetral, 4-8, 15-30 ...: número de golpes perimetrales, PX: proximal y DS: distal.

1. Sin marcado perimetral. Se efectuó tomando el hueso por un extremo y golpeando el otro cerca del tercio distal o proximal contra el borde agudo de un yunque de granito en sentido transverso al eje del hueso. El seccionamiento se obtuvo con un golpe contundente, aunque en pocas ocasiones fue necesario un segundo. Una variante de esta técnica consistió en un golpe con percutor de filo sobre el hueso apoyado en un yunque con filo transverso con resultado negativo: se produjo el astillamiento masivo del hueso.

2. Con MP de entre 4 a 8 golpes controlados (no muy fuertes). Se aplicaron en el perímetro del tercio distal o proximal de la diáfisis (como en los restantes casos). Dada la fragilidad natural de los huesos, los golpes de mayor intensidad invariablemente producían rajaduras. Se utilizó como percutor una lasca grande de toba silicificada con filo en ángulo de unos $40^{\circ}$ y de unos $200 \mathrm{~g}$, con el hueso sostenido en la mano sin apoyarlo. En principio se efectuó el MP con el hueso apoyado sobre yunque de piedra pero al producirse múltiples fisuras se desechó esta modalidad. El seccionamiento se efectuó, como en las restantes variantes de MP, mediante un golpe sobre yunque de roca con filo transverso, intentando hacer coincidir el punto de impacto con el MP.

3. Con MP de entre 15 y 30 percusiones, en condiciones como las de la técnica anterior.

4. Con MP de más de 40 percusiones. El tiempo insumido en cada experiencia fue de entre 45 segundos y 1 minuto 35 segundos.

5. Con MP mediante surco por aserrado. Se utilizaron lascas de filo natural y/o retocado con dorso, de sílice, con ángulo entre 30 y $45^{\circ}$. El tiempo insumido en cada experiencia fue de entre 1 minuto 40 segundos y 2 minutos 30 segundos. El ancho del surco, de sección en v, osciló entre 1,5 y $2,8 \mathrm{~mm}$ y la profundidad entre 0,5 y $1,2 \mathrm{~mm}$ (aprox. entre $1 / 6$ y $1 / 3$ de la pared ósea).

\section{Comentarios sobre la experiencia}

Los tipos de fracturas obtenidos fueron ordenados según los atributos de ángulo y de forma, discriminando entre fracturas transversales, oblicuas (muy leve a muy acentuada) y longitudinales, y según la forma del borde de fractura; sea regular, irregular o astillada (Fig. 4 y Tabla 3). El número reducido de

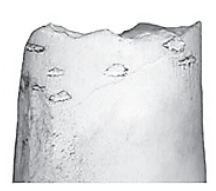

$\mathbf{a}$

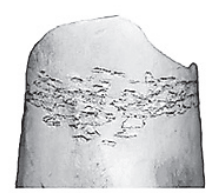

b

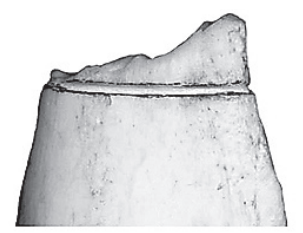

c

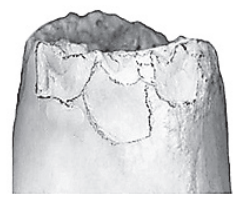

d

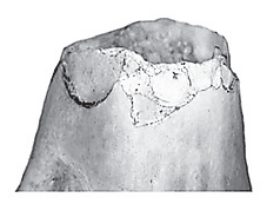

e

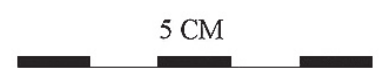

Fig. 5: Detalle de extremos articulares de Cervus elaphus utilizados en la experiencia. a) fémur ds. con rastros del marcado perimetral por entre 15 y 30 golpes, b) fémur px. con MP por más de 40 golpes, c) tibia px. con surco por aserrado, d) - e) fémur ds. y px. utilizados como machacadores. 
experiencias efectuadas con cada técnica no hace conveniente el manejo de porcentajes, aunque podemos destacar algunas tendencias. En la Fig. 5 se muestra el aspecto del hueso luego de la aplicación de algunas de las técnicas empleadas.

Para fines prácticos, se reunieron las experiencias con fractura transversal y con fractura oblicua muy leve por un lado y las que resultaron con las restantes variantes de fracturas oblicuas por el otro (Fig. 6). Así, se obtuvieron nueve experiencias con fractura transversal, treinta y cinco con fracturas oblicuas y sólo una con fractura longitudinal.

Sin marcado perimetral, por fractura por un solo golpe, todas las fracturas resultaron oblicuas, en su mayoría acentuadas o muy acentuadas con astillamientos. No parece haber mayores diferencias entre la técnica de 4-8 golpes y la de 15-30, mientras que en la de más de 40 golpes se observa un incremento de fracturas transversales y oblicuas leves. El número de experiencias con fractura transversal aumentó en la medida en que la técnica de MP por percusión se hizo más compleja, mientras que llegó a su punto más alto en la técnica del aserrado. Si el aserrado perimetral hubiese sido más profundo se habrían obtenido más experiencias con fracturas transversales y más casos con bordes regulares. Como las primeras experiencias por aserrado mostraron su eficacia y predictibilidad, no insistimos mayormente en ella. Las fracturas en el fémur, el húmero y en menor medida en el radio-cúbito, todos con torsión sigmoidea, resultaron más oblicuas y/o astilladas.

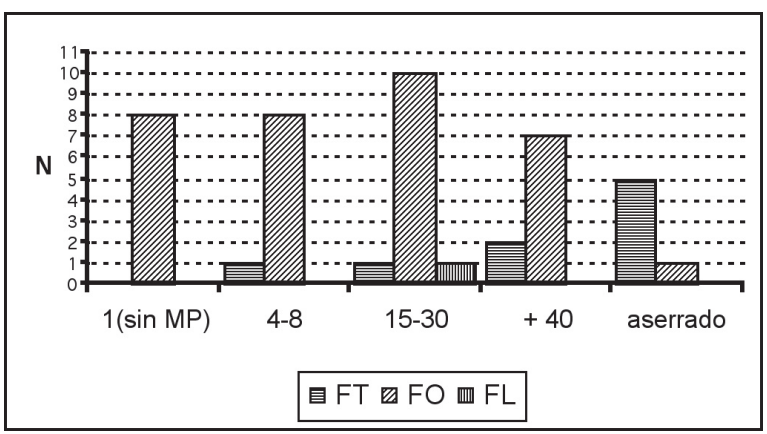

Fig. 6 Tipos de fracturas por cada técnica de fractura transversal. N: número de experiencias, SFT: sumatoria de fractura transversal y fract. oblicua muy leve, SFO: sumatoria de fract. oblicua leve a fract. oblicua muy acentuada (ver Tabla 3), FL: fract. longitudinal, 1 (sin MP): un golpe, sin marcado perimetral, $4-8$...: número de percusiones del MP.

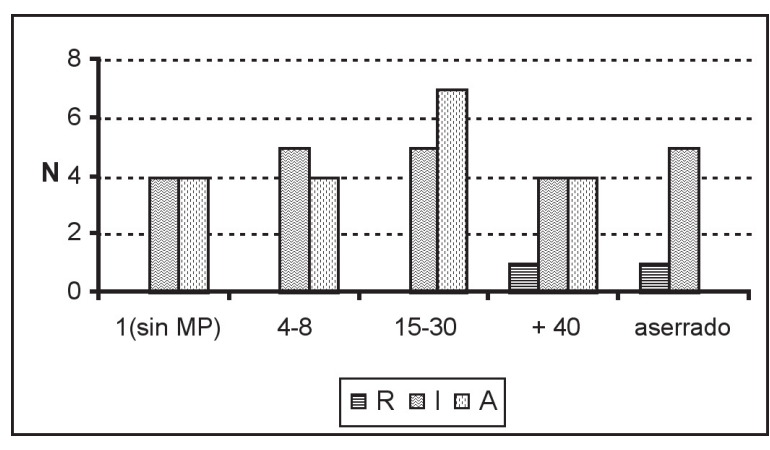

Fig. 7: Forma de las fracturas por cada técnica de fractura transversal. R: regular, I: irregular, A: astillada, $1(\sin \mathrm{MP})$ : un golpe, sin marcado perimetral, 4-8 ...: número de percusiones del MP.

En cuanto a la forma de los bordes de fractura para todas las variantes (Tabla 3 y Fig. 7), las fracturas regulares se dieron sólo en las técnicas por aserrado y por más de 40 golpes. En la de aserrado no hubo terminaciones astilladas. En las restantes técnicas, los extremos astillados se mantienen en números similares. Con las terminaciones irregulares sucede algo parecido, aunque la proporción sube en la técnica del aserrado. Como hemos visto, las fracturas regulares son muy escasas.

Las terminaciones de las fracturas oblicuas adoptaron diferentes formas en sus partes salientes (transversal, en punta y convexa) y entrantes (transversa, en V y cóncava). Los extremos salientes transversos también permitirían en mayor o menor medida el uso del hueso como machacador, pese a reducirse la superficie activa.

Todas las técnicas de FT utilizadas dejaron marcas tanto en el extremo articular buscado como en los fragmentos de la diáfisis opuestos (Fig. 5a, b, c). En el MP por percusión, los golpes produjeron pequeñas hendiduras muy superficiales en forma de segmentos o depresiones romboidales alargadas de dos a tres $\mathrm{mm}$ de longitud. La sucesión de hendiduras de percusión produjo una especie de surco superficial de entre 5 y $10 \mathrm{~mm}$ de ancho y menos de $1 \mathrm{~mm}$ de profundidad.

Las partículas de hueso desprendidas por el MP por percusión son de ínfimo tamaño, no superando los $3 \mathrm{~mm}$ de largo. En un caso de surco por percusión, la sucesión de golpes quizás más fuertes que en otras experiencias, produjo escasos lascados adventicios laterales sobre las caras externa e interna de la diáfisis y en el plano de fractura. Estos últimos lascados se originaban más frecuentemente 
en el momento del golpe contra el yunque para el seccionamiento del hueso, en general en poca cantidad y aislados.

Por lo visto hasta aquí las diferentes técnicas para la obtención de la FT no provocaron modificaciones semejantes a las conocidas en la bibliografía como de "marcado o surco perimetral" o a las producidas durante el machacado, como veremos más adelante. En ningún caso se produjo sucesión de negativos de lascados (con aspecto "escamoso" o "escamoso escalonado").

En todas las técnicas se produjeron fisuras longitudinales a oblicuas de mayor o menor importancia, tanto durante el mismo MP por percusión como más frecuentemente en el golpe posterior de seccionamiento contra el yunque. Estas fisuras debilitan la pared del hueso y favorecen desprendimientos. En la mayoría de las experiencias de cada técnica se produjeron desprendimientos de diáfisis del mismo extremo articular y de la diáfisis media, que produjeron en general entre 1 a 4 fragmentos, hasta 10 en el caso de la técnica por un solo golpe. Las fracturas obtenidas en las diferentes experiencias frecuentemente se desviaron de la línea formada por el MP, incluso separándose varios centímetros en un caso, coincidiendo parcialmente la mayoría de las veces y totalmente en pocas ocasiones. En un caso de percusión por un solo golpe resultó una fractura oblicua leve irregular reproducida en el extremo opuesto al impactado. Los huesos frescos se mostraron muy frágiles, mientras que los que fueron expuestos al aire unos días resultaron más resistentes.

De las cinco técnicas de seccionamiento experimentadas para obtener la fractura transversal, la del MP por aserrado resultó la más eficiente, seguida por el MP por percusión por más de 40 golpes. Las técnicas más sencillas (por un golpe o por 4 a 8 golpes) no dieron el resultado esperado. Lo mismo observaron Mengoni y Silveira (1976:264) en el caso del aserrado, al efectuar la experimentación de fracturas transversales.

En total resultaron 19 huesos (41,30\% del total de experiencias) con fracturas entre transversales y oblicuas potencialmente útiles como machacadores, aunque frecuentemente el perímetro útil se vio reducido por la forma de la fractura. Otros huesos con fracturas más oblicuas pudieron haber sido acondicionados por golpes posteriores o por el mismo uso.
Simulación del uso de los huesos con

\section{FT como machacadores óseos}

Para esta parte de la experiencia manejamos las hipótesis, entre otras, de que estos instrumentos fueron utilizados en el machacamiento de carne fresca dura o de carne deshidratada (charqui), para facilitar su consumo. Nos adelantamos aquí a la problemática de la aplicación que tuvo el instrumento, tema sobre el cual volveremos más adelante, en la discusión.

Para efectuar la experiencia se seleccionaron siete extremos articulares con fractura transversal y oblicua muy leve: 1 fémur px. y 3 ds. y 1 tibia px. y 2 ds. Se machacó piel fresca de ciervo (doble), carnes frescas "duras" y charqui de potro, sobre un rodado granítico con superficie aplanada lisa a modo de yunque. La forma de sujetar el hueso fue con la palma de la mano sobre la epífisis. Los instrumentos se utilizaron en cada experiencia entre 10 y 30 minutos. Los golpes fueron moderados, sin implicar mayores esfuerzos.

En la experiencia se distinguieron tres modificaciones principales del borde de fractura del hueso producidas durante el machacado (Fig. $5 \mathrm{~d}$ y e, Fig. 8 y Fig. 9d, e y f):

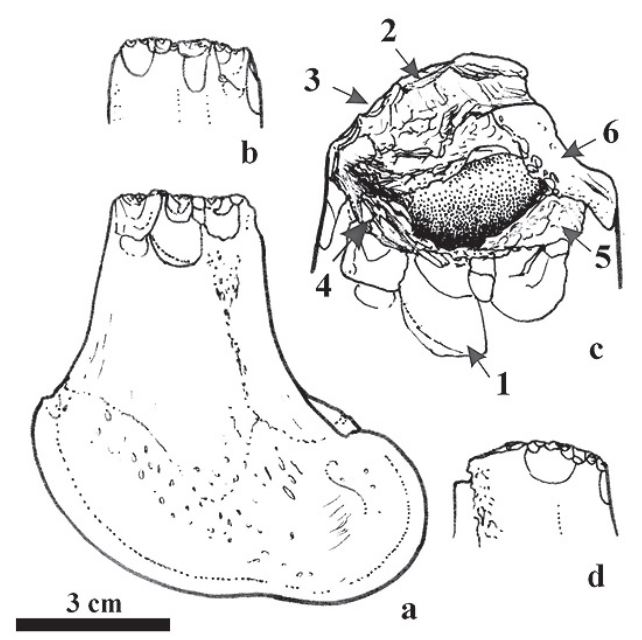

Fig. 8 Machacador experimental sobre extremo ds. de fémur der. de Cervus elaphus. a) vista lateral interna, b) anterior, c) detalle de la superficie activa, d) lat. externa. 1: negativos de lascados laterales, 2: negativos de lascados contiguos en el plano de fract., 3: filo, 4: lascas adheridas contiguas con talones y pequeñas astillas deformadas por aplastamiento, 5 : superficie roma y 6: superficie de fractura sin rastros de uso. 
1. Negativos de lascados laterales orientados según el eje longitudinal del hueso, que parten desde el borde activo del instrumento (plano de fractura transversal) y se proyectan sobre la superficie externa e interna de la diáfisis (Fig. 5d y e, Fig. 8c y Fig. 9d, e y f). Los desprendimientos reiterados de estas lascas laterales tienden a destacar un único filo más o menos continuo, que se reactiva en sucesivos golpes (Fig. 8c). La sucesión de desprendimientos de lascas laterales externas suele producir negativos de aspecto "escamoso" escalonado.

Las lascas desprendidas de la superficie externa de la diáfisis suelen ser escamosas, delgadas, de talón filiforme, con presencia de bulbo no destacado y con esbozo de ondas de percusión. El talón puede mostrar un filo "mellado" o "romo". El extremo distal de la lasca suele ser convexo, en forma de filo delgado. En algunos casos el extremo distal es menos convexo a recto oblicuo, asociado a la presencia de charnela. La relación ancho-largo es variable; por ejemplo algunas medidas son: $13 \mathrm{~mm}$ de ancho por $10 \mathrm{~mm}$ de largo y menos de $1 \mathrm{~mm}$ de espesor, 6 por 12, 6 por 11,4 por 2,5 mm. Las lascas laterales internas tienden a ser más reducidas.

2. Superficies compuestas por la sucesión de lascas adheridas (no desprendidas) y pequeños negativos de lascados contiguos en el plano de fractura (Fig. 8c). Los talones filiformes de las lascas forman una sucesión de filos paralelos a la pared del hueso. En ocasiones los talones de estas lascas se encuentran plegados, deformados por aplastamiento.
3. En sectores más espesos y resistentes del plano de fractura se observan superficies romas (Fig. 8c). Estos espesores mayores del hueso minimizan los desprendimientos que forman filos.

\section{Comentarios sobre la experiencia}

La experimentación simulativa permitió asociar directamente y en todas sus variantes las modificaciones producidas por el uso de los instrumentos experimentales como machacadores con las observadas en el material arqueológico analizado, que nosotros interpretamos como machacadores.

Las características de las lascas y otros desprendimientos producidos durante el machacado se diferencian claramente de las originadas durante la percusión para el marcado perimetral. Es importante destacar que en el machacado los desprendimientos se producen por impactos según el eje longitudinal del hueso, mientras que en el marcado perimetral se dan en el sentido transverso a dicho eje.

Cabe destacar también que los lascados laterales internos y externos más evidentes durante el machacado se produjeron cuando el material procesado se adelgazaba y los golpes se daban prácticamente sobre el yunque de piedra. De no ser así, los lascados demoraban en aparecer, sin llegar a ocultar los rastros del surco por aserrado o percutido. Esta situación sería diferente con el uso más intensivo del artefacto.
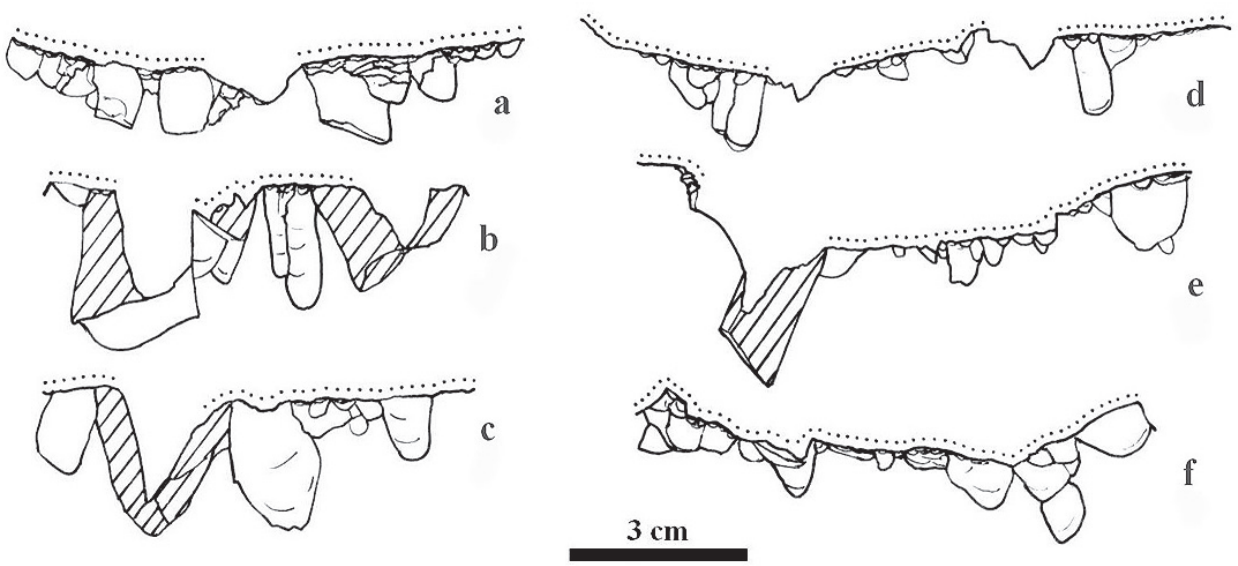

Fig. 9: Perímetro desdoblado de bordes activos de machacadores arqueológicos del sitio Hill Station; a) fémur ds., b) tibia ds. y c) fémur ds. y experimentales de Cervus elaphus; d) fémur ds., e) tibia px. y f) fémur px. La línea de puntos indica sectores con rastros de uso y el rayado oblicuo planos de fractura sin modificaciones. 
Las modificaciones óseas por machacado no se observan en sectores entrantes del plano activo, ya que éstos no entran en contacto con la superficie que ofrece resistencia durante el machacado. Las partes salientes de una fractura transversa irregular durante el machacado pueden reducirse hasta regularizar el plano de fractura o bien pueden provocar la pérdida de partes de la pared diafisaria, dejando entrantes. Esto último se vio favorecido en el caso de existir fisuras preexistentes originadas a raíz de la fractura transversal del hueso. La presencia de este tipo de fisuras reduce la utilidad del instrumento.

Ante el protagonismo arriba mencionado del yunque en la producción de los lascados óseos durante la experiencia, se hizo una experiencia de aplicación del machacador óseo en el trabajo bifacial de talla y retalla de una lasca gruesa de toba silicificada. Durante el trabajo se fue girando el machacador para que los golpes se repartieran sobre el perímetro activo. Las modificaciones sobre el hueso son similares a las obtenidas por el machacado de carne sobre piedra, aunque las lascas desprendidas suelen ser más frecuentes y espesas por el trabajo más violento.

\section{DISCUSIÓN Y CONCLUSIONES}

\section{Los machacadores óseos}

A la luz de los resultados obtenidos hasta el momento, consideramos que las modificaciones óseas comúnmente asociadas con el "marcado o surco perimetral" en extremos articulares de huesos largos de guanaco no son producto de una particular técnica para producir la fractura transversal, sino que son el resultado del uso del hueso como instrumento en actividades que implicaron machacar o percutir. La experimentación simulativa de técnicas de producción de fractura transversal y del uso de los huesos como machacadores de material orgánico (carne dura y charqui) sobre yunque de piedra permitió confirmar esta hipótesis.

A modo de breve resumen, hasta el momento podemos decir que los machacadores óseos son instrumentos expeditivos que en Patagonia fueron confeccionados sobre extremos articulares de huesos largos de guanaco principalmente, aunque también se los encuentra en huesos de Rehidae y de huemul. Incluyen la epífisis, en general, entre
1/3 y 1/5 de la diáfisis. Su distribución espaciotemporal conocida en Patagonia es amplia, desde el noroeste patagónico hasta el norte de Tierra del Fuego y la costa atlántica, encontrándoselos en sitios y ambientes diferentes y con cronologías que abarcan desde tiempos prehispánicos tardíos hasta el Holoceno Temprano. La frecuencia con que aparecen en el registro arqueológico oscila entre el 5 y el 20\% con respecto al total de extremos articulares recuperados. Son instrumentos no formatizados, es decir sin modificar su forma original más allá de la fractura misma del hueso. Son artefactos simples, con una zona activa localizada en el perímetro del plano transverso de rotura de la diáfisis, opuesto a la epífisis. Se lo sujetó por la epífisis, haciendo percutir el extremo transverso de la diáfisis en el sentido longitudinal del hueso. Este uso como machacador produjo el desprendimiento sucesivo de lascas delgadas laterales cuyos negativos se orientan según el eje longitudinal del hueso y parten desde el perímetro activo. En la cara externa de la diáfisis, la sucesión de negativos de lascados suele dar un aspecto "escalonado" o "escamoso". En el plano de fractura se observan negativos de lascados y lascas adheridas contiguas, cuyos talones filiformes pueden aparecer como una sucesión de filos paralelos a la pared del hueso, en ocasiones formando un único filo más o menos continuo o como pequeñas astillas deformadas por aplastamiento. Otras superficies se muestran melladas, romas. Suele faltar parte del perímetro activo, por desprendimientos mayores de la diáfisis producidos durante la fractura original del hueso o durante el uso.

Hasta el momento hemos registrado más de 35 sitios arqueológicos en Patagonia con menciones de "MP" o con indicación sugerente. En 20 de ellos pudimos constatar que se trata de los artefactos que motivaron este trabajo, con 101 ejemplares analizados. Interpretamos que en los restantes sitios las citas de "MP" podrían remitir al mismo tipo de material. En este sentido, hemos notado que luego de las primeras menciones del "marcado perimetral" en nuestro medio (Mengoni y Silveira, 1976 y Silveira 1979), el término se incorporó a la literatura como expresión resumida y significativa del sentido original que le dieron estos autores, que nosotros interpretamos de la forma que ya hemos expuesto, como observamos en el mismo material de Silveira (1979). 
Pensamos que también podría ser el caso de parte del material etnográfico de los Dassanetch de África estudiado por Gifford-González (1989), ya comentado en los antecedentes bibliográficos.

Si bien en principio podríamos pensar que la fractura transversal de estos huesos se habría logrado por alguna técnica determinada, la bibliografía consultada no deja clara la presencia y menos las características de esta supuesta técnica. Como se mencionó antes, en el material arqueológico al que hemos tenido acceso no observamos vestigios de marcado perimetral, aunque es cierto que el uso de estos instrumentos expeditivos (poco o nada formatizados) puede ocultar los posibles rastros de manufactura. El marcado perimetral, de haberse aplicado, sería el único rasgo vinculado con la intención de lograr un instrumento.

La falta de evidencias de MP en el material arqueológico por el momento nos lleva a poner en duda si realmente existió una técnica determinada para la producción de las fracturas transversales en los extremos articulares de guanaco. Quizás lo que tradicionalmente se vio como fractura transversal regular resulta ser una fractura despareja que luego se fue regularizando con el uso mismo del hueso como machacador, como en parte hemos observado en la experiencia. En este campo de incertidumbre en el cual incursionamos, podríamos pensar que de la masa de extremos articulares remanentes de la partición de los huesos para la extracción de la médula, por ejemplo, se habrían obtenido algunos ejemplares que podían utilizarse o acondicionarse expeditivamente como machacadores. Esto se podría haber logrado mediante golpes en los extremos salientes de las diáfisis o por machacado directamente sobre piedra. Esta situación incluiría tanto a los huesos frescos como a los secos en buen estado, con lo cual aumentaría la materia prima disponible. El remontaje de astillas de diáfisis con los machacadores arqueológicos podría echar luz sobre este tema, ya que en los sectores no modificados por el uso deberían verse rastros de la supuesta técnica de marcado perimetral utilizada.

La "novedosa" inclusión de los extremos articulares de huesos largos antes conocidos como "MP" dentro de la categoría de instrumentos lleva a plantear si deben ser considerados o no en los cómputos del material arqueofaunístico. Casiraghi (1985:67) propuso que los artefactos "expeditivos" pueden incluirse en el MNI (se entiende en general en los cálculos de abundancia taxonómica y anatómica).

Los cazadores de guanaco de Patagonia tuvieron en general amplia disponibilidad de materia prima para la confección de instrumentos óseos como los machacadores. Estos instrumentos en el mejor de los casos habrían sido muy poco formatizados (de haber existido una técnica de MP), donde el tiempo y el esfuerzo necesarios para su obtención habrían sido mínimos, aunque no es posible afirmar lo mismo sobre su uso. Los machacadores pudieron ser utensilios "descartables" obtenidos como beneficio secundario del consumo, con lo cual quizás no fueron conservados en los traslados de un sitio a otro y habrían ingresado al registro casi como un resto faunístico más. También pueden haber sido reutilizados dentro del mismo sitio en sucesivas ocupaciones, con lo cual no dejarían de formar parte del conjunto arqueofaunístico del sitio, aunque su historia tafonómica sería distinta. Sin embargo, no hay que descartar del todo su eventual conservación dentro del conjunto estable de útiles (tool kit) en determinadas condiciones.

Por el momento consideramos que este tipo de artefactos debe ser incluido tanto en las listas de instrumental como en las del material arqueofaunístico.

Sobre las posibles aplicaciones

de los machacadores óseos

Volvemos aquí al tema de los posibles usos de este instrumento, que por el momento mantenemos en el plano hipotético.

Dentro del contexto cazador, los huesos representan una fuente de materia prima importante, cuyo uso depende del tipo de actividades que se desarrollen y de la oferta de otras materias primas (Scheinsohn 1997). En este trabajo proponemos que los machacadores óseos pudieron haber sido utilizados para procesar material orgánico, probablemente carne, fibra vegetal, etc. Los resultados de la experimentación apoyarían esta hipótesis, aunque tampoco se puede descartar algún tipo de aplicación en el trabajo de talla-retalla de material lítico, aplicación que nos parece menos probable.

Cabe pensar que en miles de años de economía cazadora-recolectora, los cazadores de guanaco han 
de haber desarrollado formas de aprovechar mejor la carne de sus presas. En este sentido, vamos a exponer algunas consideraciones sobre nuestras hipótesis de que estos machacadores pudieron haber sido utilizados en el ablandamiento de carne deshidratada (charqui) y de carne fresca dura.

El charqueo es una técnica de conservación de la carne de amplia difusión geográfica y temporal. El contexto arqueológico y etnohistórico de Patagonia nos indica que el guanaco fue el principal recurso económico, en general disponible en abundancia. En fuentes etnohistóricas de Patagonia se cita el uso y machacado de charqui en diferentes situaciones.

Schmid (1964:177) menciona que entre los años 1858 y 1865: ... Si en el campamento hay carne en abundancia; cortan los cuartos traseros en lonjas largas y delgadas, colgándolas de un palo a secar; ésta es tarea de las viejas. La carne así secada se asa lo mismo que la fresca y se come con grasa de avestruz, o bien se machaca sobre una piedra hasta tornarla blanda y fibrosa y se sirve mezclada con grasa de avestruz...

En 1869 Musters (1964:133) comenta que en un campamento tehuelche. ...se charquean las ancas, esto es, se corta la carne en tajadas finas, $y$, después de echarle un poco de sal, se seca al sol. Cuando está bien seca, se asa al rescoldo, apretada entre dos piedras y mezclada con grasa de avestruz o de otra clase; esta preparación, como el pemican, es muy conveniente para el que hace un largo viaje, porque ocupa poco lugar y un simple puñado satisface el apetito. Ante el fracaso de una excursión de caza, también menciona que las mujeres ... se apresuraron a moler un poco de charqui... (Musters 1964:221).

Por otro lado el viajero Claraz indica el aprovechamiento intensivo de la presa mediante el charqueo en momentos de escasez: ...Comimos un costillar, el pecho y el cogote. De lo demás se hizo charqui, sin desperdiciar nada. El hambre había aleccionado a los indios... (Claraz 1988 [1865-1866]: 95).

En nuestro país algunos autores se han preocupado por detectar indicios del "consumo diferido" por charqueo (De Nigris y Mengoni Goñalons 2002) en material zooarqueológico. Las evidencias en ese sentido estarían dadas por la presencia de huellas de corte producidas durante la preparación de las partes para el charqueo (Haber et al. 1991) y por la representación diferencial de partes esqueletarias (Miller 1979 y Browman 1989 en Haber et al. 1991, De Nigris y Mengoni Goñalons 2002 y De Nigris 2003).

Por otro lado y en cuanto al machacado de las carnes "duras", la carne de un animal recién cazado puede ser difícil de digerir de inmediato, ante el stress de su persecución y muerte o estado de desnutrición, por la edad avanzada del animal o por sus características según su posición anatómica. Ciertas situaciones, como la escasez momentánea de mejores presas o el mismo stress nutricional del indígena, habrían hecho necesario el consumo de estas carnes "duras".

El consumo de carne fresca dura y de charqui habría demandado un procesamiento previo. Las carnes frescas "duras" se pueden tiernizar por machacado, como hoy mismo se hace con los martillos o machacadores de madera o aluminio que se venden para ese fin o con otro tipo de artefacto. Estos martillos traen un extremo con superficie plana y el opuesto con puntas a modo de pirámides truncas. La parte plana permite el adelgazamiento y tiernización de la carne por desplazamiento de las fibras musculares, mientras que la superficie con puntas produce la rotura de las fibras, con lo cual se logra una mejor tiernización. Los machacadores óseos pudieron haberse utilizado en el pasado al modo de estos martillos, por el hecho mismo de facilitar el consumo de la carne para el común de las personas, desde el simple placer de comer carne tierna hasta reducir el desgaste dentario; o para facilitar la ingesta en niños con dientes sin erupcionar o poco desarrollados y en ancianos con dientes muy desgastados o faltantes.

Considerando este tipo de aplicación para los machacadores óseos, no pueden descartarse los machacadores de piedra o madera con la misma función ya que en Patagonia la oferta de materia prima lítica para la confección de machacadores habría sido alta. Actualmente, informantes de extracción rural del noroeste patagónico procesan el charqui de potro machacándolo con piedra o martillo de hierro sobre yunque de piedra. Es de suponer que se hayan usado rocas naturales en el machacado de carne, aunque no se las menciona en el registro arqueológico.

Con el fin de contrastar el rendimiento de los machacadores de piedra y de hueso, se incorporó 
en la experiencia el uso de machacadores de piedra. Los machacadores óseos se mostraron eficaces para el ablandamiento de carne fresca dura, produciendo la rotura regular de las fibras fácilmente y sin mayor esfuerzo. El machacador de piedra produjo en parte el desplazamiento de las fibras elásticas, haciendo menos controlable la operación. En cuanto al charqui, el machacador de piedra resultó más eficiente debido a que el esfuerzo necesario para vencer la resistencia de este material, rompiendo las fibras rígidas, fue menor al que demandaba el machacador de hueso.

En este trabajo creemos haber aportado pruebas suficientes de que los materiales estudiados fueron instrumentos utilizados como machacadores, con lo cual nos queda claro su función, aunque no así su aplicación. Las hipótesis que manejamos sobre el uso de estos instrumentos no agotan las posibilidades en ese sentido; éste es aún un capítulo abierto que nos invita a manejarnos con cautela, profundizando estas hipótesis y explorando otras. La búsqueda de micro-rastros y de probables restos de los materiales procesados en los bordes activos de machacadores óseos en buen estado de conservación puede orientar sobre el o los materiales que se procesaron con estos instrumentos. También una experimentación más controlada sobre distintos elementos a machacar o percutir y los rastros resultantes puede orientar en este sentido.

Paradójicamente, nuestro largo camino de análisis e interpretación nos llevó a converger con los resultados que había obtenido J. B. Bird ya en 1936 sobre la función de estos artefactos. Vaya este trabajo como modesto reconocimiento a su labor pionera. Esperamos que nuestro aporte abra nuevos campos de análisis que puedan contribuir al esclarecimiento del rol que cumplieron estos instrumentos en la vida de los cazadores-recolectores de Patagonia.

\section{AGRADECIMIENTOS}

Deseamos dejar constancia de nuestro agradecimiento a las siguientes personas: a Mario Silveira, Augusto Cardich, Laura Miotti y Luis Borrero por brindarnos cordialmente el acceso a material de estudio; a Sergio Caviglia por la gentileza de facilitarnos información original inédita; al Dr. Craig Morris y Sumnru Aricanli del American Museum of Natural History por el acceso al material de la colección Bird; a Ana Albornoz y Vivian Scheinsohn por la lectura crítica del manuscrito; a Ana Aguerre, Cristian Becker, Teresa Civalero, Mariana De Nigris, Dolores Elkin, Rafael Goñi, Alfredo Prieto y M. Vázquez porque de una forma u otra colaboraron con este trabajo. Al comercio Ahumadero Familia Weiss de San Carlos de Bariloche por cedernos el material para la experimentación. Pedimos disculpas por alguna omisión involuntaria. Lo expresado en este trabajo es de responsabilidad exclusiva de los autores.

\section{BIBLIOGRAFÍA}

ACOSTA, A. 2000. Huellas de corte relacionadas con la manufactura de artefactos óseos en el nordeste de la provincia de Buenos Aires. Relaciones de la Sociedad Argentina de Antropología, XXV:159-177.

AGUERRE, A. M. 1994. Restos óseos guanaco del Alero Charcamata. Contribución a la Arqueología del río Pinturas, provincia de Santa Cruz. Editado por C. J. Gradín y A. M. Aguerre. Editorial Búsqueda de Ayllu, Entre Ríos, Argentina.

BIRD, J. B. 1993 [1936]. Viajes y arqueología en Chile Austral. Editado por John Hyslop, Ediciones de la Universidad de Magallanes, Chile.

BORRERO, L. A. 1994-1995. Arqueología de La Patagonia. Palimpsesto, 4:9-69, Buenos Aires.

BORRERO, L. A., N. V. FRANCO, F. M. CARBALLO y F. MARTIN 1998-1999. Arqueología de Estancia Alice, Lago Argentino. Cuadernos del Instituto Nacional de Antropología y Pensamiento Latinoamericano, 18:31-48.

CASIRAGHI, M. 1985. Comentarios referentes al estudio de los artefactos óseos. Comunicaciones de las 1ras. Jornadas de Arqueología de la Patagonia, Serie Humanidades, 2:65-68, Gobierno de la Provincia del Chubut.

CAVIGLIA, S. y L. A. BORRERO. 1978. Bahía Solano: su interpretación paleoetnozoológica en un marco regional. En prensa en Actas del V Congreso Nacional de Arqueología Argentina, San Juan, Abril de 1978.

CLARAZ, J. 1988. Diario de viaje de exploración al Chubut 1865 1866. Estudio preliminar y mapa por R. Casamiquela, Ed. Marymar, Buenos Aires.

DE NIGRIS, M. E. 2005. El consumo en grupos cazadores recolectores. Un ejemplo zooarqueológico de Patagonia Meridional. Sociedad Argentina de Antropología. (Tesis de Doctorado).

DE NIGRIS, M. E. y G. L. MENGONI GOÑALONS. 2002. El guanaco como fuente de carne y grasas en Patagonia. Resúmenes de ponencias de las Quintas Jornadas de Arqueología de la Patagonia, 27 al 31 de mayo de 2002, Buenos Aires.

FRANCO, N. V., L. A. BORRERO, J. B. BELARDI, F. CARVALLO MARINA, F. M. MARTIN, P. CAMPAN, C. F. DUBOIS, N. STADLER, M. I. HERNÁNDEZ LLOSAS, H. CEPEDA, A. S. MUÑOZ, F. BORELLA, F. MUÑOZ e I. CRUZ. 1999. Arqueología del cordón baguales y sistema lacustre al sur 
del Lago Argentino (Provincia de Santa Cruz, Argentina). Praehistoria 3:65-86.

GIFFORD-GONZÁLEZ, D. P. 1989. Ethnographic analogues for interpreting modified bones: some cases from East Africa. En: Bone modification, editado por R. Bonnichsen y M. H. Sorg, pp. 179-246. Orono: Center for the Study of the First Americans.

GRADÍN, C. J. 1976. Parapetos de piedra y grabados rupestres de la meseta del lago Buenos Aires, Actas y Memorias del IV Congreso Nacional de Arqueología Argentina, Tomo III (1/4):315-337, San Rafael, Mendoza.

GRADÍN, C. J., C. A. ASCHERO y A. M. AGUERRE. 1976. Investigaciones Arqueológicas en la Cueva de Las Manos Estancia Alto Río Pinturas (Provincia de Santa Cruz). Relaciones de la Sociedad Argentina de Antropología, 10 (N.S.):201-250.

HABER, A. F., S. AHUMADA, J. FERREIRA y M. JIMÉNEZ. 1991. De la carnicería al almacén. Hacia la identificación arqueológica del charqueo: un estudio de caso. Shincal 3(1):219-233, Catamarca.

HAJDUK, A., A. M. ALBORNOZ y M. J. LEZCANO. 2004. El "Mylodon" en el patio de atrás. Informe preliminar sobre los trabajos en el sitio El Trébol, ejido urbano de San Carlos de Bariloche, Provincia de Río Negro. Contra Viento y Marea. Arqueología de Patagonia. Actas de las Quintas Jornadas de Arqueología de la Patagonia (mayo del 2002), pp. 715-731. Compiladores: M. T. Civalero, P. M. Fernández y A. G. Guráieb, Buenos Aires.

MANSUR, M. E., A. LASA y M. VÁZQUEZ. 2004. Investigaciones arqueológicas en Punta Bustamante, provincia de Santa Cruz: el sitio RUD01BK. Contra Viento y marea. Arqueología de Patagonia. Actas de las Quintas Jornadas de Arqueología de la Patagonia (mayo del 2002), pp. 755774. Compiladores: M. T. Civalero, P. M. Fernández y A. G. Guráieb, Buenos Aires.

MARTIN, F. M. 2004. Tendencias tafonómicas en el registro óseo humano del norte de Tierra del Fuego. En: Temas de Arqueología. Arqueología del norte de la Isla Grande de Tierra del Fuego. Compilado por Luis Alberto Borrero y Ramiro Barberena. Editorial Dunken, Buenos Aires.

MASSONE, M., D. JACKSON y A. PRIETO. 1993. Perspectiva Arqueológica de los Selk'nam. Colección de Antropología, Centro de Investigaciones Diego Barros Arana, Universidad de Magallanes y Dirección de Bibliotecas, Archivos y Museos, Chile.

MENA L. F. y D. JACKSON S. 1991. Tecnología y subsistencia en Alero Entrada Baker, Región de Aisén, Chile. Anales del Instituto de la Patagonia, Serie Ciencias Humanas, 20:169-203, Punta Arenas, Magallanes, Chile.

MENGONI GOÑALONS, G. L. 1982. Notas zooarqueológicas I: fracturas en huesos. En: Actas del VIII Congreso Nacional de Arqueología, Colonia del Sacramento, Uruguay, 5 al 8 de diciembre de 1980.

MENGONI GOÑALONS, G. L. 1988. Análisis de materiales faunísticos de sitios arqueológicos. Xama 1:71-120, Mendoza, Argentina.

MENGONI GOÑALONS, G. L. 1999. Cazadores de guanacos de la estepa patagónica. Sociedad Argentina de Antropología. Colección Tesis Doctorales, Buenos Aires.

MENGONI GOÑALONS, G. L. y M. J. SILVEIRA. 1976. Análisis e interpretación de los restos faunísticos de la Cueva de las
Manos, Estancia Alto Río Pinturas (Provincia de Santa Cruz). Relaciones de la Sociedad Argentina de Antropología, 10 (N.S.):261-270.

MENGONI GOÑALONS, G. L. y M. E. DE NIGRIS. 1999. Procesamiento de huesos largos de guanaco en Cerro de Los Indios I (Santa Cruz). Soplando en el viento ... Actas de las Terceras Jornadas de Arqueología de la Patagonia, pp. 461:475.

MIOTTI, L. 1998. Zooarqueología de la meseta central y costa de Santa Cruz. Un enfoque de las estrategias adaptativas aborígenes y los paleoambientes. Revista del Museo de Historia Natural de San Rafael, 10(1/4), Mendoza.

MUÑOZ, A. S. 1999. El registro arqueofaunístico del sitio Campo del Lago 2. Implicancias para el estudio de los procesos de formación del registro arqueológico en la costa del lago Argentino (Provincia de Santa Cruz, Argentina). Praehistoria 3:105-118.

MUÑOZ, A. S. 2000. El procesamiento de guanacos en Tres Arroyos 1, Isla Grande de Tierra del Fuego. Desde el país de los Gigantes, Perspectivas Arqueológicas en Patagonia, Tomo 2:499-517 de las Actas de las IV Jornadas de Arqueología de la Patagonia (1998), Río Gallegos.

MUÑOZ, A. S. y J. B. BELARDI. 1998. El marcado perimetral en los huesos largos de guanaco de Cañadón Leona (colección Junius Bird): implicaciones arqueofaunísticas para Patagonia Meridional. Anales del Instituto de la Patagonia, Serie Ciencias Humanas, 26:107-118, Punta Arenas, Magallanes, Chile.

MUSTERS, G. Ch. 1964 [1869-1870]. Vida entre los patagones. Un año de excursiones por tierras no frecuentadas, desde el Estrecho de Magallanes hasta el río Negro. Estudio preliminar y notas de Raúl Rey Balmaceda. Ediciones Solar/Hachette, Buenos Aires.

NAMI, H. G. 1999. Arqueología en la localidad arqueológica Pali Aike, cuenca del Río Chico (Provincia de Santa Cruz, Argentina). Prehistoria 3:189-218.

NAMI, H. G. y FLORENCIA BORELLA. 1999. Investigaciones actualísticas-experimentales aplicadas a la interpretación de huellas de cercenamiento en restos arqueofaunísticos de cetáceo de Tierra del Fuego. Anales del Instituto de la Patagonia, Serie Ciencias Humanas, 26:239-254, Punta Arenas, Magallanes, Chile.

PINOTTI, L. V. 2000-2002. "Yeguarizo también comemos". Cuadernos del Instituto Nacional de Antropología y Pensamiento Latinoamericano, 19:525-533.

PRIETO, A., F. MORELLO, R. CÁRDENAS y M. CHRISTENSEN. 1998. Cañadón Leona: a sesenta años de su descubrimiento. Anales del Instituto de la Patagonia, Serie Ciencias Humanas, 26:83-105, Punta Arenas, Magallanes, Chile.

SCHEINSOHN, V. 1997. Explotación de materias primas óseas en la Isla Grande de Tierra del Fuego. Tesis Doctoral inédita.

SCHMID, T. 1964. Misionando por Patagonia austral (1858-1865). Academia Nacional de la Historia, Buenos Aires.

SEMENOV, S. A. 1981. Tecnología Prehistórica (estudio de las herramientas y objetos antiguos a través de las huellas de uso). Akal Universitaria, serie: Arqueología, Akal editor, Madrid.

SILVEIRA, M. J. 1979. Análisis e interpretación de los restos faunísticos de la Cueva Grande del Arroyo Feo (Provincia de Santa Cruz). Relaciones de la Sociedad Argentina de Antropología, 13 (N.S.):229-254. 